\title{
Prevalence and Risk Factors Associated with Intestinal Parasitic Infections among Food Handlers of Swat, Khyber Pakhtunkhwa, Pakistan
}

\author{
Wali Khan $^{1, *}$, Noor-un-Nisa ${ }^{2}$, Aly Khan ${ }^{3}$ \\ ${ }^{1}$ Department of Zoology, University of Malakand, Chakdara, Lower Dir, Khyber Pakhtunkhwa, Pakistan \\ ${ }^{2}$ Vertebrate Pest Control Institute, Southern Zone- Agricultural Research Centre, Pakistan Agricultural Research Council, Karachi \\ University Campus, Karachi \\ ${ }^{3}$ Crop Diseases Research Institute, Southern Zone- Agricultural Research Centre, Pakistan Agricultural Research Council, Karachi \\ University Campus, Karachi \\ *Corresponding author: walikhan.pk@gmail.com
}

\begin{abstract}
Intestinal parasitic infection is one of the public health problems in developing countries including Pakistan. Food handlers being major source, therefore effective prevention and control require the identification of local risk factors. Presently occupation based cross sectional study was conducted to assess the prevalence of intestinal parasitic infections and associated risk factors among food handlers of district Swat, Khyber Pakhtunkhwa, Pakistan from January 2011 to December 2013. Study subjects were selected based on random sampling methods. A total of 267 food handlers were enrolled, socio-demographic data and possible factors for the occurrence of intestinal parasitic infection were collected using a pre-tested structured questionnaire. Approximately 10 grams of stool specimens were examined using wet mount and formal ether concentration technique. The overall prevalence of intestinal parasite was 83.1\% ( $\mathrm{n}=222 / 267)$. Multiple infections were identified in 28.4\% ( $\mathrm{n}=76 / 267)$ individuals. These infections were given in order of their frequency and percentage as: Ascaris lumbricoides 55.8\% (n=149/267) Trichuris trichuira 14.9\% ( $\mathrm{n}=40 / 267)$, Entamoeba histolytica /dispar 14.2\% (38/267), Enterobius vermicularis 9.73\% ( $\mathrm{n}=26 / 267)$, Hymenolepis nana 9.36\% $(\mathrm{n}=25 / 267)$, Taenia saginata $8.98 \%(\mathrm{n}=24 / 267)$, Hookworm 5.99\% $(16 / 267)$ and Giardia lamblia 5.61\% $(\mathrm{n}=15 / 267)$. Hand washing before food handling, preparing food during suffering from infectious diseases and using common knife for cutting the flesh or vegetable were the most significantly associated factors for the occurrence of intestinal parasite infection. The results highlighted that food handlers with different pathogenic organisms may influence consumers to significant health risks. Routine screening and treatment of food handlers is a proper tool in preventing food-borne parasitic diseases.
\end{abstract}

Keywords: intestinal parasitic infection, farmers, Swat, Khyber Pakhtunkhwa, Pakistan

Cite This Article: Wali Khan, Noor-un-Nisa, and Aly Khan, "Prevalence and Risk Factors Associated with Intestinal Parasitic Infections among Food Handlers of Swat, Khyber Pakhtunkhwa, Pakistan.” Journal of Food and Nutrition Research, vol. 5, no. 5 (2017): 331-336. doi: 10.12691/jfnr-5-5-7.

\section{Introduction}

Parasitic infection is highly prevalent throughout in developing countries of the world. Food handlers are a potential source of infection for many intestinal parasites and other enteropathogenic infections as well [1].

Parasites are one of the important casual agents of diarrhea, loss of weight, abdominal pain, nausea, vomiting, lack of appetite, abdominal distention and Iron deficiency anemia [2]. Most of the remote areas of Pakistan are suffered due to this potential hazards, parasitic infections are the major public health problem and most of the victims are children.

Scholars claimed that factors such as low household income, poor personal and environmental sanitation, over-crowding, limited access to clean water, tropical climate and low altitude significantly associated with the occurrence of high intestinal parasitic infections especially in tropical and sub-tropical areas [3] In Pakistan, intestinal parasitic infection is one of the challenging issue, causes morbidity amongst children. Different studies conducted in different regions of the world, depicted that the prevalence and possible associated factors are different.

Intestinal parasite prevalence was higher in children with less educated mother, in children who have habit of eating raw/ unwashed vegetables, drinking unprotected well/spring water and who do not have hand washing practice before meal [4].

Intestinal parasitic infections are widely prevalent, with variable distribution in different parts of the country. Various surveys have been conducted, some of them are as: [5-17]. There is a need for the periodical evaluation of the prevalence for future intervention in high risk group such as food handlers. The present study was aimed to assess the prevalence of intestinal parasitic infections and associated factors among food handlers in district Swat, Pakistan. 


\section{Material and Methods}

\subsection{Study Area}

District Swat is located 165 Kilometer away from the capital city, Peshawar. The elevation of Swat river valley, at the southern boundaries of the district, is over 600 meters and rises rapidly towards the north. There are several mountain peaks ranging from 4500 to over 6000 meter above sea level. Average temperature ranges -2 to $33^{\circ} \mathrm{C}$. The area is predominantly rural and most residents live in villages.

\subsection{Study Design and Period}

A cross sectional study among food handlers of district Swat (age in years $<20$ and $>20$ in both the genders) from January 2012 to December 2013 was conducted.

\subsection{Source and Study Population}

The source population was food handlers. Total reported area of the district is 506528 hectares out of which only 98845 (19.5\%) hectares is cultivable. Most of the cultivation is being carried out in the southern parts of the area. The managers of the food communities were interviewed. Food handlers were randomly selected and are seemed healthy and did not take any anti-helminthic drug before a month were this study population.

\subsection{Sampling Method and Procedure}

Thirty managers of 267 food handlers were sampled and single sampling technique was used. The sample size was determined using single population proportion formula by considering the prevalence of intestinal parasites in food handlers that give a final sample size of 267.

\subsection{Data Collection and Laboratory Procedures}

The interviewers were informed in advance about the purposes and contents of the survey. Data about the socio demographic characteristics and other associated factors were collected using a semi structured based questionnaire. At least 10 gram of stool specimen was collected using clean, tightly corked, leak proof containers, a small amount was analyzed using wet mount technique and the remaining portion was concentrated using formal - ether concentration technique and examined microscopically [18].

\subsection{Data Quality Control}

To assure the reliability of data collection, a study questionnaire was prepared in English and translated to the local language (Urdu) and retranslated in to English in order to assure consistency. Before the questionnaire was used in the actual data collection it was pre tested on 30 food handlers' managers. Stool sample collection and investigation was made according to a standard procedures. Microscopic reading was made by the first author and results were confirmed by himself.

\subsection{Ethical Considerations}

Ethical clearance was obtained from the Ethical review committee of University of Karachi, Pakistan. Communication with the University administrators was made through formal letter obtained from University. After that, verbal and written consent was obtained from each participants. In order to keep confidentiality of any information provided by study subjects, the data collection procedure was anonymous. Study participants who were positive for intestinal parasitic infection were informed for appropriate treatment protocol by the concerned physicians.

\section{Results}

\subsection{Socio-Demographic Characteristics}

Of the total expected 300 participants, 267 were participated in the study, making the response rate of $89 \%$. The mean age of the respondents was 27.5 with a standard deviation of \pm 19 .3. The study participants were male 156 [58.4\%] and female 111 [41.5\%]. The population surveyed were comprised below 20 years in age 100 [37.5\%] and above 20 years 167 (62.5\%) respectively [Table 1].

\subsection{Socio-economic Characteristics}

The risk factors like hand washing before food handling, preparing food when suffering from diseases and using common knife for cutting the flesh or vegetable are significantly $(<0.05)$ associated with intestinal parasitic infections while hand washing after toilet and finger nail status are not statistically $(>0.05)$ associated with the prevalence of these infections. [Table 2].

Table 1. Socio-demographic characteristics of food handlers in district Swat, Khyber Pakhtunkhwa, Pakistan (2011- 2013)

\begin{tabular}{|c|c|c|c|}
\hline Variable & & Frequency & Percentage (\%) \\
\hline \multirow{2}{*}{ Age } & Below 20 years & 100 & 37.4 \\
\hline & Above 20 years & 167 & 62.5 \\
\hline \multirow{2}{*}{ Sex } & Male & 156 & 58.4 \\
\hline & Female & 111 & 41.5 \\
\hline \multirow{2}{*}{ Altitude } & low & 110 & 41.1 \\
\hline & high & 157 & 58.8 \\
\hline \multirow{3}{*}{ literacy } & Can't read and write & 134 & 50.1 \\
\hline & Read and write & 87 & 32.5 \\
\hline & Regular education & 23 & 8.61 \\
\hline
\end{tabular}


Table 2. Association between intestinal parasitic infections and socioeconomic factors in Food handlers of low and high altitude in Swat, Pakistan

\begin{tabular}{|c|c|c|c|c|c|}
\hline \multicolumn{2}{|l|}{ Risk factors } & Infected & $\%$ of infection & odds ratio (95\%CI) & $P$ value \\
\hline \multirow{2}{*}{ Hand washing after toilet } & With water only & 87 & 32.5 & \multirow{2}{*}{$1.006(0.6984$ to 1.448$)$} & \multirow{2}{*}{0.4877} \\
\hline & With water and soap & 135 & 50.5 & & \\
\hline \multirow{2}{*}{ Hand washing before food handling } & With water only & 186 & 69.6 & \multirow{2}{*}{$0.5778(0.3678$ to 0.9076$)$} & \multirow{2}{*}{0.0083} \\
\hline & With water and soap & 36 & 13.4 & & \\
\hline \multirow{2}{*}{$\begin{array}{l}\text { Preparing food when suffering from diseases } \\
\text { like diarrhea, cold etc }\end{array}$} & Yes & 177 & 66.2 & \multirow{2}{*}{$0.6756(0.4423$ to 1.032$)$} & \multirow{2}{*}{0.0344} \\
\hline & no & 45 & 16.8 & & \\
\hline \multirow{2}{*}{$\begin{array}{l}\text { Using common knife for cutting the flesh or } \\
\text { vegetable }\end{array}$} & Yes & 193 & 72.2 & \multirow{2}{*}{$0.51849(0.3192$ to 0.841$)$} & \multirow{2}{*}{0.0036} \\
\hline & No & 29 & 10.8 & & \\
\hline \multirow[t]{2}{*}{ Finger nail status } & Trimmed & 187 & 70.0 & \multirow{2}{*}{$0.7927(0.4941$ to 1.272$)$} & \multirow{2}{*}{0.1674} \\
\hline & Non-trimmed & 35 & 13.1 & & \\
\hline
\end{tabular}

Table 3. Frequency distribution of intestinal parasites identified from food handler stools

\begin{tabular}{|l|l|l|}
\hline Parasite species & Population infected & Prevalence (\%) \\
\hline Ascaris lumbricoides & 149 & 55.8 \\
\hline Trichuris trichura & 40 & 14.9 \\
\hline Enterobius vermicularis & 26 & 9.73 \\
\hline Hook worms species & 16 & 5.99 \\
\hline Taenia saginata & 24 & 8.98 \\
\hline Hymenolepis nana & 25 & 9.36 \\
\hline Entamoeba histolytica & 38 & 14.2 \\
\hline Giardia lamblia & 15 & 5.61 \\
\hline
\end{tabular}

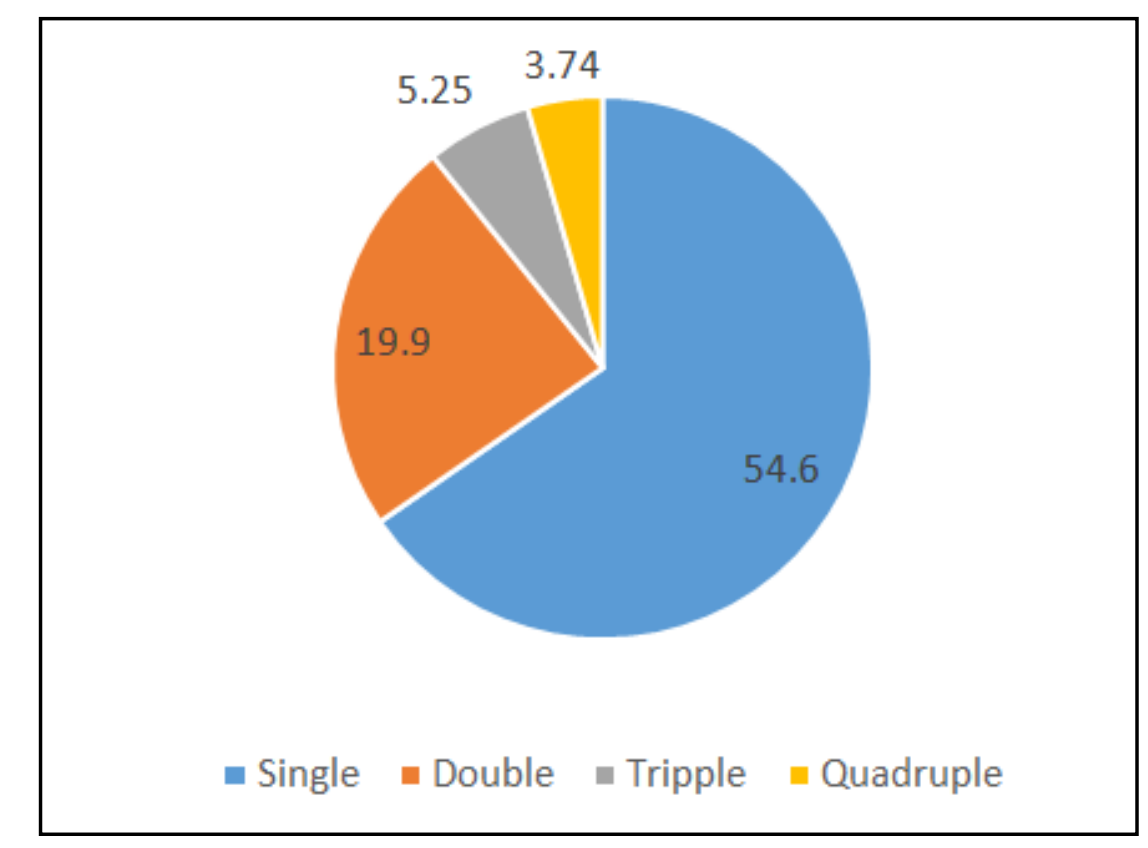

Figure 1. Pattern of infection in food handlers of Swat, Khyber Pakhtunkhwa, Pakistan

Table 4. Pattern of mono-parasitism of intestinal parasitic infections in food handlers of Swat, Pakistan

\begin{tabular}{|c|c|c|c|}
\hline Type of infection & No. Of species & Species associated & Cases (\%) \\
\hline Mono-parasitism & 1 species (n=146) & Ascaris lumbricoides & $73(27.3)$ \\
\hline & & Trichuris trichura & $17(6.36)$ \\
\hline & & Enterobius vermicularis & $11(4.11)$ \\
\hline & & Hook worm & $05(1.87)$ \\
\hline & & Taenia saginata & $14(5.24)$ \\
\hline & & Hymenolepis nana & $09(3.37)$ \\
\hline & & Entamoena histolytica & $12(4.49)$ \\
\hline & & Giardia lamblia & $05(1.87)$ \\
\hline Total mono-parasitism & & $146(54.6)$ \\
\hline Total of infected patients & & & $222(83.1)$ \\
\hline Total samples examined & & & 267 \\
\hline
\end{tabular}


Table 5. Pattern of poly-parasitism of intestinal parasitic infections in food handlers of district Swat, Pakistan

\begin{tabular}{|c|c|c|c|}
\hline Poly-parasitism & 2 species $(n=52)$ & A.lumbricoides + T.trichuira & $07(2.62)$ \\
\hline & & A.lumbricoides + E.histolytica & $23(8.61)$ \\
\hline & & A.lumbricoides + E.vermicularis & $04(1.49)$ \\
\hline & & A.lumbricoides + H.nana & $15(5.61)$ \\
\hline & & A.lumbricoides + Hookworm & $03(1.12)$ \\
\hline \multirow[t]{5}{*}{ Sub-total } & & & $52(19.4)$ \\
\hline & 3 species $(n=14)$ & A.lumbricoides + T.trichuira + E.histolytica & $02(0.74)$ \\
\hline & & A.lumbricoides + T.trichuira + hookworms & $08(2.99)$ \\
\hline & & A.lumbricoides + E.vermiculris + H.nana & $01(0.37)$ \\
\hline & & A.lumbricoides + E.vermicularis + T.saginata & $03(1.12)$ \\
\hline \multirow[t]{4}{*}{ Sub-total } & & & $14(5.24)$ \\
\hline & 4 species $(n=10)$ & A.lumbricoides + T.trichuira + E.vermicularis + E.histolytica & $03(1.12)$ \\
\hline & & A.lumbricoides + hookworm + E.vermicularis + T.saginata & $04(1.49)$ \\
\hline & & A.lumbricoides + T.trichuira + T.saginata + G.lamblia & $03(1.12)$ \\
\hline Sub-total & & & $10(3.74)$ \\
\hline Total parasitism & & & $76(28.4)$ \\
\hline Total of infected patients & & & $222(83.1)$ \\
\hline Total samples examined & & & 267 \\
\hline
\end{tabular}

Flow- chart of the selected food handler's categories for the present study at high and low altitude.

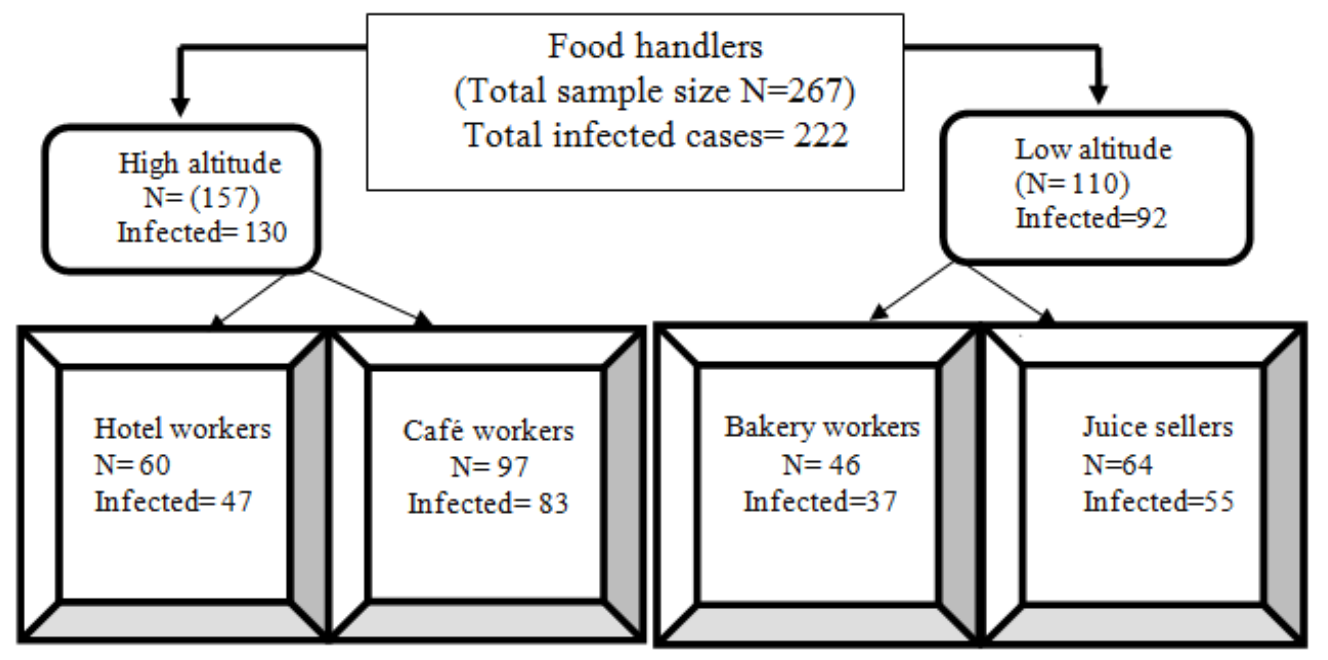

Figure 2. Food handlers companies, total samples and infected for the present investigation

\subsection{Prevalence of Intestinal Parasite Infection}

The overall prevalence of intestinal parasite was $83.1 \%$ ( $n=222 / 267)$. Multiple infections were identified in $28.4 \%$ $(n=76 / 267)$ individuals. These infections were given in order of their frequency and percentage as: Ascaris lumbricoides $55.8 \% \quad(\mathrm{n}=149 / 267) \quad$ Trichuris trichuira 14.9\% ( $\mathrm{n}=40 / 267)$, Entamoeba histolytica /dispar 14.2\% (38/267), Enterobius vermicularis 9.73\% ( $\mathrm{n}=26 / 267)$, Hymenolepis nana 9.36\% ( $\mathrm{n}=25 / 267)$, Taenia saginata 8.98\% (n=24/267), Hookworm 5.99\% (16/267) and Giardia lamblia 5.61\% (n=15/267). Table 4 and Table 5, Figure 1.

\subsection{Pattern of Prevalence}

The prevalence of intestinal parasites to at least a single infection was 146 (54.6\%). Mixed infection was observed in $76(28.4 \%)$ among food handlers who had intestinal parasitic infection. Of these, proportion 52 (19.4\%) are double, 14 (5.24\%) triple and 10 (3.74\%) quadruple infections were noted (Table 3 and Table 4).

\section{Discussion}

Intestinal parasitic infections are normally associated to living conditions, level of poverty, personal and environmental hygiene, availability of clean water supply, adequacy of health facilities and sanitation practices. Over all prevalence of intestinal parasites seen in present study was higher than those reported in Pakistan [6,7,8,9,19,11,12,13,20,21]. This is due to the fact that these studies dealt with targeted groups i.e. children living in slums, rural children or those with gastrointestinal problems that are expected to have higher prevalence of the parasites, [14,15,16,17] and reported the comparable findings. The parasite species found in present study are similar to those reported earlier and no parasite specific to the region was recorded. Association of parasitic infection with different factors like low and high altitude, sex and age of the food handlers, hand washing after toilet, hand washing before food handling, preparing food when suffering from diseases like diarrhea, cold etc, using common knife for cutting the flesh or vegetable, finger nail status, were studied. Each of the factor studied were of considerable 
importance and having high impact on the prevalence of parasites, food handlers of $>20$ years of age had higher prevalence than younger. This may be due to the close association of aged food handlers to their practices, male food handlers were more infected than female it may be due to the fact that male usually found engaged in their activities as compared to females, food handlers of the low altitude were found more infected than high altitudes. Hand washing after toilet, hand washing before food handling, preparing food during suffering from diseases, using common knife for cutting the flesh or vegetable, were the most important factors that enhanced the prevalence of parasites.

The overall prevalence of intestinal parasite in the present study was 222/267 (83.1\%).This finding is higher than the study conducted in other parts of Pakistan [6,10,20]. Sindh Pakistan 31\% [11], however present finding was also higher than studies conducted in different parts of the world as [22,23]. While it was lower than studies conducted in Nigeria (94\%) [24,25] and Madagascar (94.4\%) [26]. Possibly the difference might be, due to the geographical location, the living and the socio economic nature of the study subjects.

The leading intestinal parasite in the present study was A.lumbricoides 149(55.8\%) which was found to be higher than studies conducted in the same area $39.0 \%$ of the infection rate was recorded by [27] noted $31.0 \%$ of prevalence of this roundworm in Kurram Agency, Lahore (24.4\%) [28] and other countries such as Ivory Cost (38.3\%) [29]. The reason might be the geography of the place or the socio economic condition of the study area and the habit of the study participants in relation to wash hands before and after touching the food.

The second and the third most prevalent intestinal parasites in our study was T.trichuira 40 (14.9\%). The prevalence of this nematode parasite was lower than other studies done in Karachi [30,12]. Our finding was also higher than the study conducted in Wondo Genet (0.35\%) [24]. Moreover, the prevalence of E.vermicularis was 26 (9.73\%) lower than a study conducted in Vehari under developed area of Pakistan and urban and sub-urban population of Islamabad $13.8 \%$ infection were observed [31]. Prevalence was close in school children in Islamabad (9.1\%) [32] and Swat, Pakistan (8.25) [15]. This could be due to difference in environmental and living conditions of the study participants.

In the present study, hookworms, constituted about 16(5.99\%). This finding was higher than the study conducted in Swat (3.64\%), a comparable figure 6.70\% was noted by [16] while studying the shepherds intestinal parasites in the same region and Jimma, 5.0\% [33]. Similarly the prevalence of $G$. lamblia in present finding was $15(5.61 \%)$ lower than studies conducted in Lake Langano (6.2\%) [34,35] in Dir upper 6.1\% [9] and 11.4\% [20] and 50.8\% [13]. The possible explanation for this difference might be occupation relation, time gap, geographical and environmental difference of the localities.

The prevalence of multiple intestinal parasitic infections was $28.4 \%$ [ $n=76 / 267]$, which was lower than that was reported from Swat earlier (38.3\%). Variation in the environmental and geographical condition, person habit and occupational activities might explain the observed fluctuation parasitic infections.
The most important considerable associated factors with the occurrence of intestinal parasitic infection were hand washing after toilet, hand washing before food handling, preparing food when suffering from diseases, using common knife for cutting the flesh or vegetable, finger nail status, were studied. Present study highlights the need for thorough investigation of intestinal parasitic infections in food handlers of Swat, Pakistan. These diseases, which have been eliminated in most areas, continues to be popular in the rural areas of Pakistan.

\section{Acknowledgments}

Food handlers of Swat district were appreciated for giving the data and faecal materials. The authors declare that they have no conflicts of interest.

\section{Conflicts of Interests}

Authors declare that they have no conflict of interest in relation to their work.

\section{References}

[1] Sharif M, Daryani A, Kia E, Rezaei F, Nasir M, Nasrol, M. Prevalence of intestinal parasites among food handlers of Sari, Northern Iran. Rev. Inst. Med. Trop. Sao Paulo. 2015; 57(2): 139-144.

[2] Evans A-C, Stephenson L-S. Not by drugs alone: the fight against parasitic helminths. World health forum. 1995; 16: 258-261.

[3] No authors listed. Prevention and control of intestinal parasitic infections. Report of a WHO Expert Committee. World Health Organ Tech Rep Ser. 1987. 749: 1-86.

[4] Asrat A-Y, Tewodros D-E, Alemayehu W-O. Prevalence and risk factors of intestinal parasites among delgi school children, North Gonder. Ethiop J Health and Biomed Sci. 2011; 3: 75-81.

[5] Haleem M-A, Akram M, Akram S. Intestinal parasitic infection in Karachi. Pakistan J. Med. Assoc. 1965; 15: 499-501.

[6] Bilqees F-M, Khan A, Ahmad A. A survey of intestinal protozoan and helminth parasites in Karachi. Pakistan J. Med. Res.1982; 21: 54-57.

[7] Nawaz M, Nawaz Y. Observations on incidence of intestinal parasitic infection in the food handlers of hostels of Peshawar University, NWFP. Bull. Zool. 1983; 1: 63-66.

[8] Shah S-H, Khaliq M-A, Subhani F. Helminth infestation in Hazara Division. J. Pakistan. Med. Assoc. 1986; 36: 11-13.

[9] Pal R-A, Subhani F. Prevalence of intestinal helminth parasites in primary school children of Dir District (NWFP).Pakistan J. Sci. Tech. 1989; 13: 99-102.

[10] Nawaz M, Nawaz Y. Preliminary observations on Giardiasis in primary school children in Quetta, Pakistan. Pakistan J. Zool.1994 26(1): 89-90.

[11] Shaik G-S, Harani M-S, Rathi S-L, Khatri P-R. Harani P-K. Pattern of intestinal parasitic infestation in Larkana. Proceedings of Parasitology. 2000; 29:61-66.

[12] Chaudry Z-H, Afzal M, Malik M-A. Epidemiological factors affecting Prevalence of Intestinal parasites in Children of Muzaffarabad district. Pakistan J.Zool. 2004; 36(4): 267-271.

[13] Kamran S-A, Bilqees F-M, Salim A. Protozoan intestinal infections fifteen months observation on in-patients and outpatients of Fatima hospital, Baqai Medical University, Karachi, Karachi, Pakistan. Proceedings of Parasitology. 2005; 40: 59-87.

[14] Khan W, Noor-un-Nisa, Khan A. An investigation on incidence of intestinal parasites under and above 15 years age in farmers of Swat, Pakistan. Proceedings of Parasitology. 2011; 52: 43-53.

[15] Khan W, Noor-un-Nisa, Khan A. Endemicity of intestinal parasites with special reference to nematodes in individuals related 
to education (Students, staff and workers) in Swat, KP, and Pakistan. Pak.J. Nemotol. 2012; 30 (1): 77-85.

[16] Noor-un-Nisa, Khan W, Khan A. Prevalence of intestinal parasites in male and female shepherds of Swat, Pakistan. Int.J.Biol.Biotech. 2011; 8 (4): 597-603.

[17] Khan W, Noor-un-Nisa, Khan A. Diversity of Intestinal Parasites in Male and Female Students and Workers of Education Department of Swat, Pakistan. Pakistan J Zool. 2015; 47(2); 65-68.

[18] Adefioye O, Efunshile A, Ojurongbe O, Akindele A, Adewuyi K, et al. Intestinal Helminthiasis among School Children in Ilie, Osun State, Southwest, Nigeria. Sierra Leon J Biomed. 2011; 3: 36-42. 17.

[19] Qureshi A-W, Tanveer A, Qureshi S-W, Maqbool A, Gill- T-J, Ali S-A. Punjab Univ. J. Zool.2005. 20: 159-168.

[20] Maqbool A, Ali S-A, Masood S. Prevalence and control of food born parasitic zoonosis in Pakistan. Aply Biol.2007; 36(1): 15-21.

[21] Tasawar Z, Lashari M-H, Anjum A, Aziz F. Human amoebiasis in Multan, Punjab, Pakistan. Journal of cell and animal biology. 2013; 7(6): 73-76.

[22] Tadesse G-I. Prevalence of intestinal helminthic infection associated risk factors among school children in Babile town eastern Ethiopia. Ethiop. J Health Dev. 2005; 19: 140-147.

[23] Yami A, Mamo Y, Kebede S. Prevalence and predictors of intestinal helminthiasis among school children in jimma zone; a cross-sectional study. Ethiop J Health Sci. 2011; 21: 167-174.

[24] Oyewole F, Ariyo F, Sanyaolu A, Oyibo W-A, Faweya T, et al. Intestinal helminthiases and their control with albendazole among primary schoolchildren in riverine communities of Ondo State, Nigeria. Southeast Asian J Trop Med Public Health. 2002; 33: 214-217.

[25] Albonico M, Shamlaye N, Shamlaye C, Savioli L. Control of intestinal parasitic infections in Seychelles: a comprehensive and sustainable approach. Bull World Health Organ. 1996; 74: 577-586.
[26] Tesfa-YohnnesT, Kloos H. Intestinal parasitism. In: Zein A.Z and Helmut Kloos (Eds).The ecology of health \& disease in Ethiopia. Addis Ababa: Ministry of Health 1998; 214-230.

[27] Ali N. A survey of intestinal parasites of man in Kurram Agency. M.Phil Thesis Department of Biological Sciences Quaid-e-Azam University Islamabad Pakistan. 1993.

[28] Akhtar T, Tehsin N, Usman S. Intestinal parasitic burden in two local hospitals of Lahore. Biologica 1993; 38; 41-48.

[29] Utzinger J, Goran E-K-N, Marti H-P, Tanner M, Langeler C. Intestinal amoebiasis, giardiasis and geoheminthiasis: their association with other intestinal parasites and reported intestinal; symptoms. Transaction of the Royal Society of tropical Medicine and Hygiene. 1999; 93: 137-141.

[30] Baqai R, Zuberi S-J, Khan M-A. J. Pakistan med. Assoc.1985; 35: 307-308.

[31] Jamil, F.A. Analysis for the prevalence of human intestinal helminth parasites in urban an suburban communities of Islamabad. M.Phil. thesis, Department of Biological Sciences, Quaid-i-Azam University Islamabad, Pakistan.1999.

[32] Pal R-A, Malik Z. Prevalence of intestinal parasites in primary school children of Islamabad. Pakistan J. Zool. 1979; 11:105-108.

[33] Amare M, Solomon G, Tesfaye K. Prevalence of intestinal parasitic infections among urban dwellers in southwest Ethiopia: a community based cross sectional study. Ethiop J Health Dev. 2007; 21: $12-17$.

[34] Matthys B, Bobieva M, Karimova G, Mengliboeva Z, JeanRichard V, et al. Prevalence and risk factors of helminths and intestinal protozoa infections among children from primary schools in western Tajikistan. Parasite \& Vectors. 2011; 4: 195.

[35] Ikram U, Ghulam S, Sabina A, Muhammad H-K. Intestinal worm infestation in primary School children in rural Peshawar. J Med Sci. 2009; 7: 2. 